\title{
The Use of Pre-recorded Lectures on Student Performance in Physiology
}

\author{
Rim Mekonnen Hadgu², Sophia Hoang-Vy Huynh² \& Chaya Gopalan ${ }^{1,2, *}$ \\ ${ }^{1}$ Department of Applied Health \& Nursing, Southern Illinois University Edwardsville, Illinois, USA \\ ${ }^{2}$ St. Louis College of Pharmacy, St. Louis, Missouri, USA \\ *Correspondence: Departments of Applied Health \& Nursing, Southern Illinois University Edwardsville, Box 1126, \\ Edwardsville, IL 62026-1049, USA. Tel: 1-618-650-5372. E-mail: cgopala@siue.edu
}

Received: January 23, 2016 Accepted: March 8, 2016 Online Published: May 12, 2016

doi:10.5430/jct.v5n1p105～URL: http://dx.doi.org/10.5430/jct.v5n1p105

\begin{abstract}
There has been an increase in reliance on pre-recorded lectures (PRL) as a source of learning in place of live-lectures (LL) in higher education today but whether PRL can effectively replace LL remains unknown. We tested how students performed in the exam questions when PRL replaced LL. While PRL+ group included those students who watched the video lectures, PRL- group was composed of students who either did not utilize these videos or accessed only briefly. Additional analysis involved the separation of exam questions, from both LL and PRL, into memory questions (MQ; basic factual details) and comprehension questions (CQ; requiring processing of the given information) and their comparisons. We did not find any significant difference in student performance between the LL and PRL groups as well as between LLMQ and PRL+MQ groups. However, students in the LL group performed significantly better on CQ compared to the $\mathrm{PRL}+$ group $(\mathrm{P}<0.05)$. Furthermore, analysis of student performance between $\mathrm{MQ}$ and $\mathrm{CQ}$ among the PRL+ and PRL- groups revealed that both groups performed significantly higher on MQ compared to CQ ( $<<0.01$ between PRL+MQ and PRL+CQ and $\mathrm{p}<0.05$ between PRL-MQ and PRL-CQ). These results suggest that LL helps students perform better on CQ, where it requires processing of given information compared to that of PRL. The effectiveness of PRL, at least from this study, is limited to mastering basic factual details but not suitable for complex conceptual processing and therefore may not fully be able to replace LL.
\end{abstract}

Keywords: live-lecture; pre-recorded lecture; student performance; memory questions; comprehension questions

\section{Introduction}

For several decades, instructors and students in higher education have attempted to record lectures for clarification, easy access, and distant educational purposes. What first started out as audio recordings on cassettes and VHS videos has steadily progressed into digital lecture recordings with advances in technology. Student dependence on these mobile lectures has increased exponentially in recent years (Beldarrain, 2006, Brown, \& Green 2007, Cardall, Krupat, \& Ulrich 2008, Colak, 2014, Copley, \& Audio, 2007, Dey, Burn, \& Gerdes, 2009, Marchand, Pearson, \& Albon, 2014, Tune, Sturek, \& Basile, 2013). As a result, most institutions have their major lecture halls equipped with tools for real-time lecture recordings (Chandra, 2011, Drouin, 2014). Online availability of recorded lectures provides flexibility for those students who are juggling the competing demands of work, studies, and other commitments. Students do utilize the lecture recordings to review course content, revise class notes, clarify complex concepts, and work at their own pace (Danielson, Preast, Bender, \& Hassall, 2014). The ability to pause or replay the recordings benefits students especially those who do not speak English as their primary or native language (Maynor, Barrickman, Stamatakis, \& Elliott, 2014, Ronchetti, 2010).

In recent years, one common form of course content delivery is pre-recorded lecture (PRL) where the instructor records a lecture outside of class and share with students in a digital format, such as MP4, that can be accessed remotely from anywhere (Shah, Cox, \& Zdanowicz, 2013). PRL has been used in lieu of live-lecture (LL) to allow more time in the classroom for active learning exercises (Armbruster, Patel, Johnson, \& Weiss, 2009, Cavanagn, 2011). The use of PRL is increasing for many other reasons such as the flipped classroom mode of teaching (Ronchetti, 2010). The traditional didactic lecture method is heavily criticized as a passive approach. The video lecturing techniques are made simpler and are affordable which allows faculty to use the same recorded lectures so that their research agenda could be strengthened. PRL is not to be confused with lecture capture (LC), which is the real-time recording of an LL that 
students can utilize to revisit lecture for various purposes (Hadgu, Huynh, \& Gopalan, 2016, Maynor, Barrickman, Stamatakis, \& Elliott, 2013).

Educators have voiced concerns and opinions on potential negative as well as positive consequences of replacing LL with PRL. One controversial outcome could be absenteeism with the availability of recorded lectures (Figlio, Rush, \& Yin, 2010, Maynor, Barrickman, Stamatakis, \& Elliott, 2013). Even if the students attended a typical lecture, it is possible that they could be distracted by their mobile devices and social media during class especially when the recorded lectures are available for them to access at a later time (Colak, 2014).

More and more institutions are beginning to phase out LL in favor of PRL for efficient information dissemination such as using class time for active learning (Cardall, Krupat, \& Ulrich, 2008, Horvath et al., 2013). However, recorded lectures may not be utilized by every student (Karnad, 2015, Williams, Birch, \& Hancock, 2012). Whether PRL can replace LL is an important question in this transition from live to recorded lectures. This notion became the interest and foundation for our study in which we replaced LL with PRL and compared student performance in the exam questions from those lectures. We later separated the questions based on Bloom's Taxonomy (Bloom, Engelhart, Furst, Hill, \& Krathwohl, 1956) from the two delivery methods, LL and PRL, to memory questions (MQ) which consisted of the basic factual details and the higher order comprehension questions (CQ) where the students were expected to process the given information to answer a question. We also studied the performance difference at both MQ and CQ levels between those who used PRL and those who did not.

\section{Methods}

Sixty Introductory Physiology students at St. Louis College of Pharmacy, 38 females and 22 males, ages 18 to 21, provided their informed consents to participate in this study. Approximately $60 \%$ of the students were female whereas $40 \%$ were male, which was consistent with the class ratio. These students were enrolled in the Introductory Physiology course for the first time after having successfully completed pre-professional sophomore level Anatomy course. This course was held during a regular semester of 16 weeks where the class met for 50 minutes, three days a week, and was taught by the same instructor. Students were provided with the course objective as well as a brief description of each topic, which would be further elaborated during lecture. The lectures were given using images from the PowerPoint slides as well as quick drawings using the document camera in order to explain individual topics. Students were given study guides to foster engagement outside the classroom. There were group activities scheduled typically once before each unit exam in order to review the topics in the form of application questions.

All class content, such as the syllabus, lecture objectives and study guides, was posted on the course management system, Moodle. Students were expected to have completed the reading assignments before class and were quizzed in every class period on the reading assignment as well as the previous day's lecture content. Teaching assistants recorded student attendance and the class had perfect attendance primarily due to the daily quiz incentive. Additionally, all students were blocked from internet access to decrease distractions related to social media and/or online video games. Cell phone restriction was enforced during class time. All lectures were given live with the exception of two lectures that were pre-recorded to replace LL. The two PRL that we utilized in this study were not intentionally chosen, but instead were given due to unforeseen circumstances that led to class cancellation. PRL were approximately 40 minutes long and included PowerPoint slides and hand-written explanations where needed, which was consistent with LL.

The course had six exams, five of which were unit exams and one was the comprehensive final. They were scheduled approximately three to four weeks apart with the exception of the fifth and the comprehensive exam, which were both given on the same day. Each exam was worth $10 \%$ of their final grade. Students who had an average of $85 \%$ on the first four exams were exempt from the final exam, but they still had to take the fifth exam. Questions from neither the fifth exam, nor the comprehensive final were included in this study given that finals week was not their normal week in a semester. Each exam consisted of 50 multiple choice questions from the new topics that were covered since the previous exam. The exam was typically written to test students' abilities to answer factual details (50\%), comprehension (35\%) and application (15\%) skills.

\subsection{Consent Forms}

Upon approval of the project by the Institutional Review Board, the written consent forms were distributed to the class size of 91 students out of which 60 students participated in this study (66\%). Signed consent forms were obtained as students enrolled in the Advanced Physiology course which was immediately after the completion of the Introductory Physiology course. Students handed their consent forms directly to the Divisional Secretary who stored them until the final grade was submitted for the Advanced Physiology course. The student names and identification numbers were 
removed and replaced with numeric codes prior to their performance analysis.

\subsection{Study Design}

The instructor-recorded lectures using Camtasia were re-recorded using Panopto, a software program with the ability to track the duration and frequency of student access. PRL was posted on Moodle, which was linked to Panopto. The recorded videos were in a streaming format and were unavailable for download to enable accurate viewing analytics. All of the students in this class were familiar with the process of accessing PRL as they were either concurrently and/or previously enrolled in other courses that expected students to use PRL as a replacement for LL.

Two lectures, blood coagulation and the role of the liver, gallbladder and the pancreas in digestion, were never given live in class but only shared in the form of recorded lectures. Students who watched at least half of the PRL comprised our PRL+ group, while students who either did not access the PRL or watched only short snippets (2 to 4 minutes) constituted the PRL- group. The questions from these two lectures were compared with that of two randomly selected lectures, the regulation of glomerular filtration and the transportation of oxygen and carbon dioxide in the blood, which served as our controls. Students that attended these two live lectures served as our LL group.

To evaluate student performance, we separated questions that came from both LL and PRL. In our study, 21 questions were derived from LL and 20 questions from PRL. We then classified the questions from each group into two subgroups: memory questions (MQ) and comprehension question (CQ). MQ referred to the recall of factual details and CQ required demonstration of deeper understanding of concepts. Although Bloom's taxonomy (Bloom, Engelhart, Furst, Hill, \& Krathwohl, 1956) includes additional hierarchy of question levels such as analysis and application, we lacked sufficient question samples to develop a valid statistical analysis for higher order questions beyond comprehension level. We were also interested to learn how the students who did not use PRL (PRL-) compared with that of those who did (PRL+) in both MQ and CQ (Figure 1).

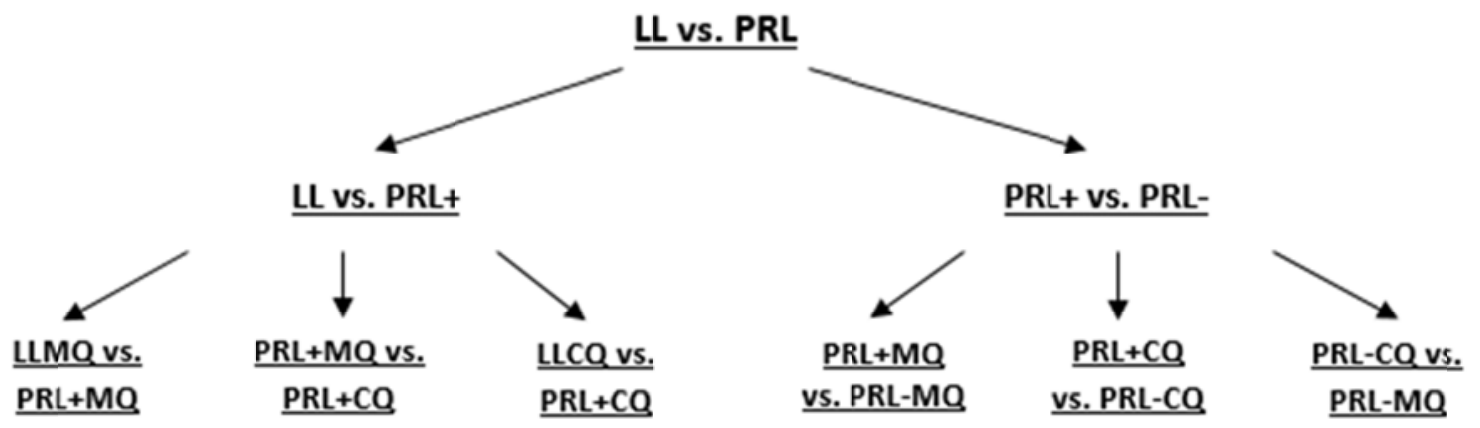

Figure 1. Summary of the Study Design

\subsection{Statistical Analysis}

One-way analysis of variance with appropriate post-test was applied using Graphpad InStat.

\section{Results}

Data analysis from the two PRL and two randomly selected LL were organized as shown in Figure 1 and the results are summarized as below.

\subsection{LL vs. $P R L+$}

Students in the LL group answered $77.7 \%$ of the questions correctly compared to $76.2 \%$ on PRL questions. These results were not statistically significant (Figure 2). 


\section{Lecture Styles and Student Performance}

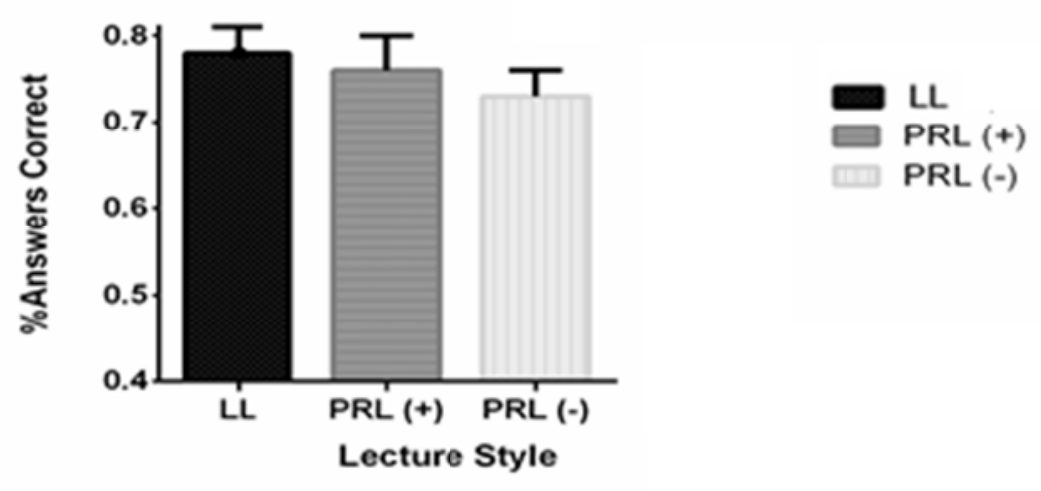

Figure 2. Student Performance in Live Lecture versus Pre-recorded Lecture

\subsection{MQ vs. CQ}

Students from the LL group had 78\% of the answers correct on CQ whereas the students from the PRL+ group had 51\% of the answers correct which was statistically significant ( $<<0.05$; Figures 3 and 5). Additionally, the percentage correct for the PRL+MQ was $81 \%$. Comparison of PRL+CQ and PRL+MQ showed a statistically significant difference $(\mathrm{p}<0.01)$. These results suggest that students performed poorly on CQ from the PRL+ group compared to the CQ from the LL group as well as the MQ from the PRL+ group.

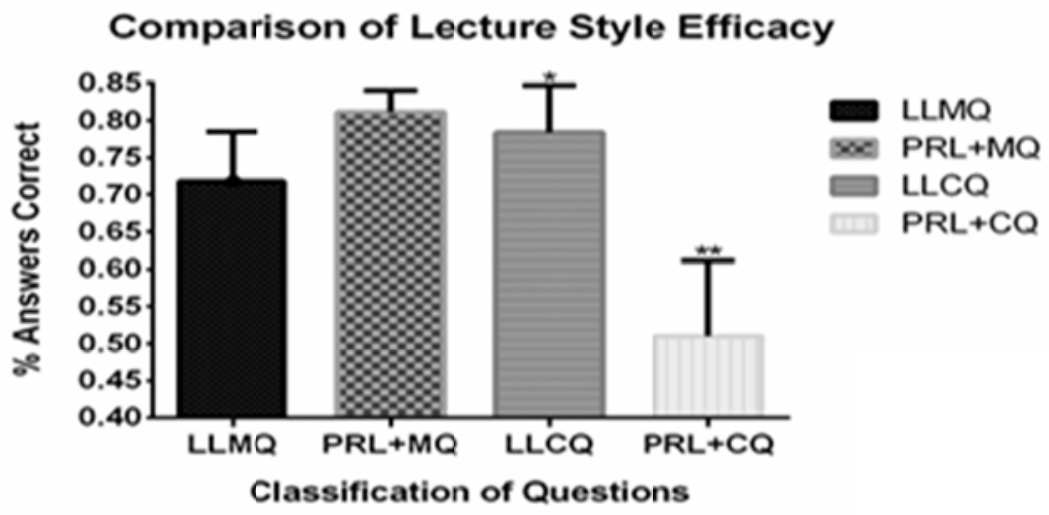

Figure 3. Comparison of Student Performance on Memory and Comprehension Questions ( ${ }^{*} \mathrm{p}<0.05$ PRL+CQ compared to LLCQ; ** $\mathrm{p}<0.01$ PRL+CQ compared to PRL+MQ)

\section{3 $P R L+$ vs. $P R L-$}

The percentage of students accessing 50\% or move of PRL was 36\%. We compared the performance of these students on exam questions who used PRL (PRL+) with those who did not (PRL-). PRL+ group had $76.2 \%$ of the answers correct whereas the PRL- group had $72.8 \%$ of the answers correct (Figure 2). These values were not significantly different suggesting that student performance was not affected by viewing of PRL or not.

\section{$3.4 M Q$ vs. $C Q$}

Although the overall comparison of PRL+ and PRL- groups suggested that there was no difference between these two groups, we further analyzed student performance on CQ and MQ of the PRL+ and PRL- groups and found that the PRL+ group obtained $81 \%$ of correct answers in MQ compared to PRL- group who had $72 \%$ of the questions correct. These numbers were not significantly different but certainly showed a downward trend for the PRL- group. On the other hand, when the performance on CQ by PRL+ group was compared with that of PRL+MQ, they had scored significantly lower on comprehension questions (PRL+CQ: 51\%; $\mathrm{p}<0.01$; Figures 3 and 6). Similarly, when the performance on CQ from the PRL- (PRL-CQ) group was compared with the performance on PRL- MQ, it was 
significantly lower (PRL-CQ: 56\%; $\mathrm{p}<0.05$ ). These results indicate that PRL+ and PRL- students perform feebly on CQ compared to MQ.

\section{Comparison of PRL+ and PRL-}

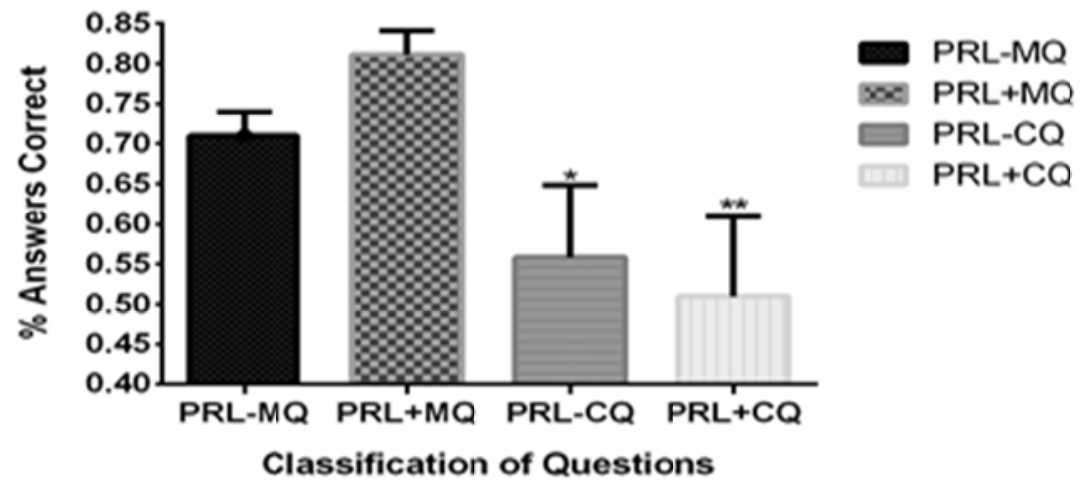

Figure 4. Comparison of Memory and Comprehension Questions of PRL + and PRL- $\left({ }^{*} \mathrm{p}<0.05\right.$ when compared to PRL-MQ; ${ }^{* *} \mathrm{p}<0.01$ when compared to PRL+MQ)

\subsection{Summary of Study Results}

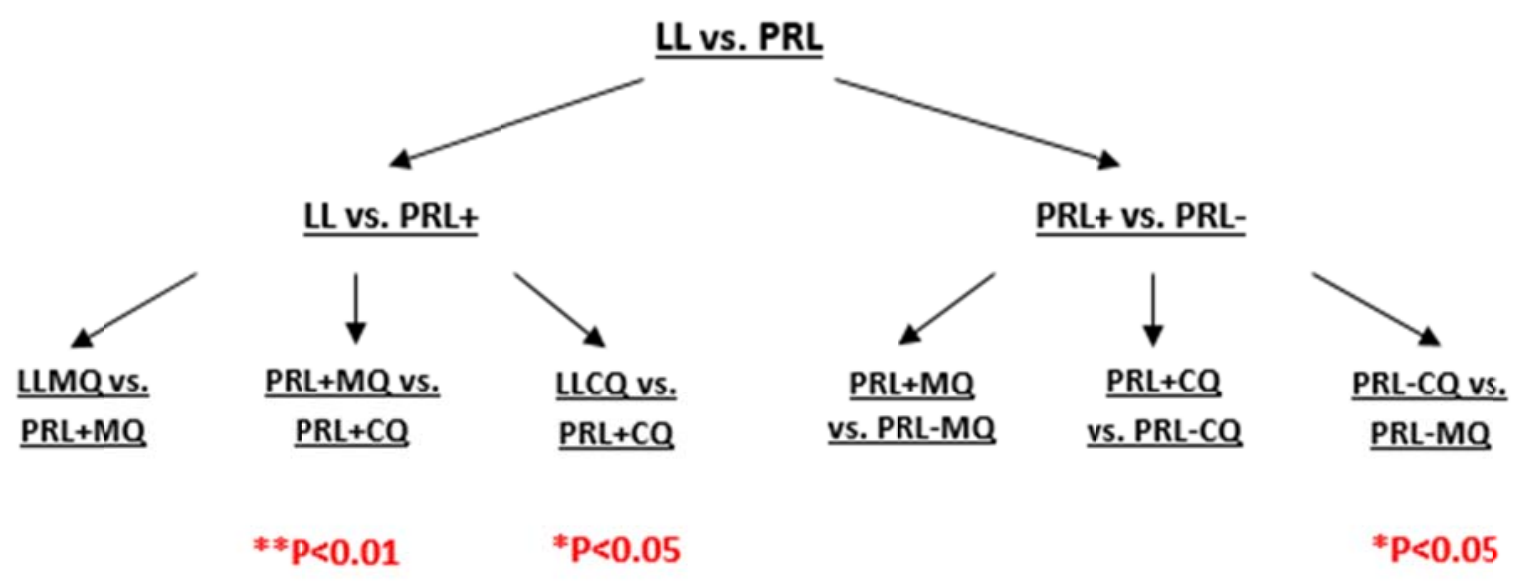

\section{Discussion}

Figure 5. Summary of the Study Results

As technology and time progresses, we can expect a shift in the statutes of student engagement and learning. There is a surge in demand for PRL either as a supplement or as a replacement for LL. The innumerable options for lecture video production, convenience of using these lectures repeatedly and its accessibility with the advancement of teaching technology has led to increased use of PRL today. Moreover, it appears that the students of the digital era may prefer to access PRL remotely than being in the classroom (O’Callaghan, Neumann, Jones, \& Creed, 2015). All of these and more have stirred concerns on our traditional didactic methods of teaching. The current study attempted to answer this dogma. Our results suggest that the in-class teaching is invaluable in students handling conceptual learning as tested by their exam performance. Whether it is related to the classroom conditions we created, where students were limited from accessing internet or cell phone to avoid distractions, which we obviously could not be imposing outside for PRL, is difficult to argue. PRL is supposed to foster students with individual responsibility to learn on their own. Students can access PRL at any time and from anywhere. But, based on our findings, not all students assumed responsibility and utilized PRL as expected because only 36\% of the students accessed PRL, and such behavior is observed by others as well (Vandsburger, \& Duncan-Daston, 2011).

Additional data exploration, where the questions were separated into MQ and CQ, students performed better on MQ in the PRL groups but not on CQ. Performance on CQ requires higher-order thinking and a greater understanding of the presented information than MQ (Bloom, Engelhart, Furst, Hill, \& Krathwohl, 1956). The statistics of the student logs 
indicated that majority of the students accessed these lectures only a day or two prior to their assigned exam. Similar observations are made by others (Groissen, Van Bruggen, \& Jochems, 2012) suggesting that students using PRL had less time to process the information that was given in the video format in comparison to LL. Other variables such as lack of motivation, lack of organization to plan scheduled study times, lack of prioritization and outside distractions could not be ignored. Other similar studies where informal feedback was received from students who used PRL suggests that they were less effective than LL because of the lack of visual stimulation and kinesics (Lovell, \& Plantegenest, 2006). With virtual lectures come the loss of a rich learning environment- an environment where instructor clarification and student-to-student engagement flourishes. This illustrates that the LL experience and interactive classroom community can prove more valuable than the actual information presented in class (Leadbeater, Shuttleworth, Couperthwaite, \& Nightingale, 2013).

PRL appears to help students perform higher in MQ than CQ. This could be due to the ability to revisit terminology or new concepts presented in the lecture videos at their own pace (Prunuske, Batzli, Howell, \& Miller, 2012) or due to the fact that students accessed these videos shortly before the exam. The ability to pause and replay the videos may aid in memorization of new information whereas in LL, students rely on their ability to take adequate notes. In fact, a student survey conducted by another study showed that students in LL reported that they spent more time on taking notes at the lecturer's pace rather than at their own (Leadbeater, Shuttleworth, Couperthwaite, \& Nightingale, 2013). Furthermore, viewing PRLs can increase MQ accuracy by providing auditory and visual cues on emphasized points that students may have missed if they were to learn the material live.

Our study, along with others, elucidates that PRL implementation can provide additional, supplementary options of study methods for students (Cardall, Krupat, \& Ulrich, 2008, Schreiber, Fukuta, Gordon, 2010). Although PRL may improve learning of factual details, its use in replacing LL may hinder students from conceptualizing complex information sometimes due to technical challenge (Rose, 2009). Furthermore, social skills and professionalism are known integral parts of the classroom experience. Reliance on only PRL may deprive students of these crucial social aspects of their learning and development into professional individuals (Karnad, 2015, Prodanov, 2012).

One limitation of this study was the small sample size of 60 students. The PRL sample size became even smaller with only $36 \%$ of student access. Another variable that could improve the study would be randomly assigning students to either PRL or LL group. Because our study was based on students' own accord, the same student could fall in both LL and PRL groups.

\section{Conclusions}

It is evident from our study that learning is more comprehensive when students are in a classroom setting rather than learning from a recorded video although the same instructor provides lecture recordings. This study suggests that automatizing learning has its limitations.

\section{Acknowledgments}

We sincerely thank Zachary Mussig for helping us access data from the course management system. We are thankful to Mariam Rehman for her assistance with part of the data analysis.

\section{References}

Armbruster, P., Patel, M., Johnson, E., \& Weiss, M. (2009). Active learning and student-centered pedagogy improve student attitudes and performance in introductory biology. CBE Life Sciences Education, 8(3), 203-213. http://dx.doi.org/10.1187/cbe.09-03-0025

Beldarrain, Y. (2006). Distance education trends: Integrating new technologies to foster student interaction and collaboration. Distance Education, 27(2), 139-153. http://dx.doi.org/10.1080/01587910600789498

Bloom, B.S., Engelhart, M.D., Furst, E.J., Hill, W.H., \& Karthwohl, D.R. (1956). Taxonomy of Educational Objectives, The classification of education goals. Handbook I: Cognitive Domain. New York, NY: David McKay Company.

Brown, A., \& Green, T. (2007). Video podcasting in perspective: The history, technology, aesthetics, and instructional uses of a new medium. Journal of Educational Technology Systems, 36(1), 3-17. http://dx.doi.org/10.2190/ET.36.1.b

Cardall, S., Krupat, E., \& Ulrich, M. (2008). Live lecture versus video-recorded lecture: Are students voting with their 
feet? Academic Medicine, 83, 1174-1178. http://dx.doi.org/10.1097/ACM.0b013e31818c6902

Cavanagn, M. (2011). Students' experiences of active engagement through cooperative learning activities in lectures. Active Learning in Higher Education, 12(1), 23-33. http://dx.doi.org/10.1177/1469787410387724

Chandra, S. (2011). Experiences in personal lecture video capture. IEEE Transactions on Learning Technology, 4(3), 261-274. http://dx.doi.org/10.1109/TLT.2011.10

Colak, M. (2014). To what extent do social network sites affect students' academic lives? Retrieved May 28, 2015 from http://www.academia.edu/7489028/Effects_of_Social_Networking_on_Students_Academic_Lives

Copley, J. (2007). Audio and video podcasts of lectures for campus-based students: Production and evaluation of student use. Innovations in Education and Teaching International, 44(4), 387-399. http://dx.doi.org/10.1080/14703290701602805

Danielson, J., Preast, V., Bender, H., \& Hassall, L. (2014). Is the effectiveness of lecture capture related to teaching approach or content type? Computers \& Education, 72, 121-131. http://dx.doi.org/10.1016/j.compedu.2013.10.016

Dey, E., Burn, H., \& Gerdes, D. (2009). Bringing the classroom to the web: Effects of using new technologies to capture and deliver lectures. Research in Higher Education, 50(4), 377-393. http://dx.doi.org/10.1007/s11162-009-9124-0

Drouin, M.A. (2014). If you record it, some won't come: Using lecture capture in introductory psychology. Teaching of Psychology, 41, 11-19. http://dx.doi.org/10.1177/0098628313514172

Figlio, D.N., Rush, M., \& Yin, L. (2015). Is it live or is it internet? Experimental estimates of the effects of online instruction on student learning. Retrieved from http://www.nber.org/papers/w16089

Gorissen, P., Van Bruggen, J., \& Jochems, W. (2012). Students and recorded lectures: Survey on current use and demands for higher education. Research in Learning Technology, 20, 297-311. http://dx.doi.org/10.3402/rlt.v20i0.17299

Hadgu, R.M., Huynh, H., \& Gopalan, C. (2016). The use of lecture capture and student performance in physiology. Journal of Curriculum \& Teaching, 5, 11-18. http://dx.doi.org/10.5430/jct.v5n1p11

Horvath, Z., O’Donnell, J.A., Johnson L.A., Karimbux, N.Y., Shuler, C.F., \& Spallek, H. (2013). Use of lecture recordings in dental education: Assessment of status quo and recommendations. Journal of Dental Education, 77(11), 1431-1442.

Karnad, A. (2015). Student use of recorded lectures: A report reviewing recent research into the use of lecture capture technology in higher education, and its impact on teaching methods and attendance. Retrieved May 28, 2015 from http://eprints.lse.ac.uk/50929/1/Karnad_Student_use_recorded_2013_author.pdf

Leadbeater, W., Shuttleworth,T., Couperthwaite, J., \& Nightingale, K. (2013). Evaluating the use and impact of lecture recording in undergraduates: Evidence for distinct approaches by different groups of students. Computers \& Education, 61, 185-192. http://dx.doi.org/10.1016/j.compedu.2012.09.011

Lovell, K., \& Plantegenest, G. (2006). Student utilization of digital versions of classroom lectures. Journal of International Association of Medical Science Education, 19, 20-25.

Marchland, J.P., Pearson, M.L., \& Albon, S.P. (2014). Students and recorded lectures: Survey current use and demands for higher education. Research \& Learning Technology, 20, 297-311.

Maynor, L.M., Barrickman, A.L., Stamatakis, M.K., \& Elliott, D.P. (2013). Student and faculty perceptions of lecture recording in a doctor of pharmacy curriculum. American Journal of Pharmaceutical Education, 77(8), 1-7.

O’Callaghan, F.V., Neumann, D.L., Jones, L., \& Creed, P.A. (2015). The use of lecture recordings in higher education: a review of institutional, student, and lecturer issues. Education \& Information Technologies, 21, 1-17. http://dx.doi.org/10.1007/s10639-015-9451-z

Prodanov, V. (2015). In-class lecture recording: What lecture capture has to offer to the instructor. Retrieved February 8, 2015 from http://digitalcommons.calpoly.edu/cgi/viewcontent.cgi?article=1339\&amp;context=eeng_fac

Prunuske, A., Batzli, J., Howell, E., \& Miller S. (2012). Using online lectures to make time for active learning. Genetics, 192, 67-72. http://dx.doi.org/10.1534/genetics.112.141754

Ronchetti, M. (2010). Using video lectures to make teaching more interactive. International Journal of Engineering 
Technologies in Learning, 5(2), 45-48. http://dx.doi.org/10.3991/ijet.v5i2.1156

Rose, K. (2009). Student perceptions of the use of instructor-made videos in online and face-to-face classes. Journal of Online Learning \& Teaching, 5(3), 487-495.

Schreiber, B.E., Fukuta, J., \& Gordon, F. (2010). Live lecture versus video podcast in undergraduate medical education: A randomized controlled trial. BMC Medical Education, 10, 10-68. http://dx.doi.org/10.1186/1472-6920-10-68

Shah, S., Cox, A.G., \& Zdanowicz, M.M. (2013). Student perceptions of the use of pre-recorded lecture modules and class exercises in a molecular biology course. Currents in Pharmacy Teaching \& Learning, 5(6), 651-658. http://dx.doi.org/10.1016/j.cptl.2013.07.011

Tune, J.D., Sturek, M., \& Basile, D.P. (2013). Flipped classroom model improves graduate student performance in cardiovascular respiratory, and renal physiology. Advances in Physiological Education, 37(4), 316-320. http://dx.doi.org/10.1152/advan.00091.2013

Vandsburger, E., \& Duncan-Daston, R. (2011). Evaluating the study guide as a tool for increasing students' accountability for reading the textbook. Journal of College Reading \& Learning, 42(1), 6-23. http://dx.doi.org/10.1080/10790195.2011.10850345

Wieling, M.D., \& Hofman, W.H.A. (2010). The impact of online video lecture recordings and automated feedback on student performance. Computers \& Education, 54(4), 992-998. http://dx.doi.org/10.1016/j.compedu.2009.10.002

Williams, A., Birch, E., \& Hancock, P. (2012). The impact of online lecture recordings on student performance. Australasian Journal of Educational Technology, 28(2), 199-213. http://dx.doi.org/10.14742/ajet.869 